\title{
Brief Analysis of Critical Realism in Chinese and Western Marine Literature
}

\author{
Yuhan YE ${ }^{1}$, Xiaoxu Chen ${ }^{2 *}$ \\ ${ }^{1,2}$ Zhejiang Ocean University, Zhoushan, China
}

*Corresponding Author: Xiaoxu Chen, Zhejiang Ocean University, Zhoushan, China

\begin{abstract}
Human life originates from the sea, and so does human culture. As a product of literary creation closely related to the sea, marine literature has a record of interaction between man and the sea. Different works of marine literature represent the social reality of different ages. This paper compares two representative works of marine literature, Chinese "Flowers in the Mirror" and Western "Gulliver's Travels", and it combines their economic and political backgrounds, compares and contrasts from the aspects of style, content and language expression, and to explore criticism of reality and its enlightenment on today's society. Some constructive suggestions are put forward on how the creation of marine literature should be created in the future.
\end{abstract}

Keywords: Analysis, critical realism, marine literature.

\section{INTRODUCTION}

The sea is the cradle of life. Human production and life are closely linked to the sea. Throughout the history of mankind, "sea" as a kind of image appears frequently in a large number of literary works. Marine literature is an indispensable part of the literary world and is developing simultaneously with human civilization. Marine literature, broadly speaking, refers to literary works related to the sea, such as literary works with the theme or background of sea. More precisely, marine literature refers to works whose theme is related to certain characteristics of the sea. It reveals phenomena in human society by describing the relationship between mankind and the sea to sublimate the theme.

Marine literature contains the author's view of social reality, which may have certain subjectivity. The author's understanding of the sea and their understanding of the social reality all affect the creation of marine literature more or less. With the change of human history and the continuous development of society, mankind's views of the sea at different ages have also been constantly changing and gradually deepening. Meanwhile, people in different countries and regions also have different views of the sea due to distinction in geography such as the proportion of the sea. Thus, their uses of the image or background of "sea" also vary.

This difference is well represented in Chinese and Western maritime literature. Compared with China, most western countries are more affected by the sea. Therefore, Chinese and Western understanding of the sea is not the same, and their social backgrounds mirrored in marine literature are also different.

\section{Current Research on Marine Literature}

\subsection{Current Research on Chinese Marine Literature}

Compared with the West, there is not much marine literature in China, but it still has been covered more or less at different periods in history. The Classic of Mountains and Rivers during the Spring and Autumn and the Warring States Period is considered as the first Chinese marine literature. After that, The Book of Songs and The Songs of Chu in Pre-Qin Dynasty, Records of the Historian in Han Dynasty all described the sea-related activities. During the Tang and Song Dynasties, poetry, as the main genre of literature at the time, presented many far-reaching marine aesthetic images, such as Bai Juyi's The Long Sea and Liu Yong's Sea Song. During the Yuan, Ming and Qing Dynasties, thanks to the Maritime Silk Road, Zheng He's seven voyage to the Western Seas greatly promoted the exchange 
of Chinese and foreign maritime communications. During this period, the number of people participating in the creation of marine literature increased rapidly, marine narrative literature developed rapidly, For example, Wu Chengen's Journey to the West regarded the sea as one of the immortals' dwellings; Luo Maodeng's The Eunuch Sambo's Journey to the West tells stories of navigation. In recent years, with the growing attention to the sea, there has been an increasing number of people who study marine literature. There are also many studies on Chinese marine literature, and different researchers have studied from different perspectives or periods (Qin Sun, 2015). For instance:

Heyong Liu, in his article entitled "A Brief History of China's Marine Literature" expounds the long historical development of Chinese marine literature from Early Qin Dynasty to Ming and Qing Dynasties, and also explains that modern Chinese marine literature, with a rich inheritance of the ancient one, will turn a new leaf (Heyong Liu, 2010).

Junyao Zhao, under the title of "Epoch Character on the Marine Literature of the Song \&Yuan Dynasty", analyzes the marine literature of the Song and Yuan dynasty in China and points out three sharp epoch characters in this period and the resulting sea consciousness, that are, its rich maritime theme highlights the innovation and development of sea literature since the pre-Qin Dynasty; its particular open social background highlights the open-mindedness and sea-oriented thinking of the marine literature; its multi-angle aesthetic pursuit highlights the value orientation of the sea strategy (Junyao Zhao, 2002).

Qingyang Guo, in his article "On the Artistic Expression of the Seas in Notes Novel of Tang and Song Dynasties: A Case Study of The Long Bearded Country and Gui Hao Drowning" uses two typical works of marine literature to analyze the narrative pattern and the phenomenon of biological personality, which shows the artistic expression of the ocean in that period (Qingyang Guo, 2013).

\subsection{Current Research on Western Marine Literature}

Western countries are closely linked to the sea, which results in an abundant supply of marine literature. Western marine literature originates from Homer's Odyssey. From the middle of the 5th century A.D., there appeared early marine literature in Britain in the form of poetry, such as Navigator, Traveler and so on. After the 16th century British society gradually established the capitalist system. The most representative work of this period was Daniel Defoe's Robinson Crusoe. At the same period, the United States also has rapid development in marine literature. James Fenimore Cooper's The Pilot, Herman Melville's Moby Dick, and Jack London's The Sea Wolf are all representatives. As an important part of the world's marine literature, Western marine literature has attracted the attention of many scholars (Qin Sun, 2015).

Randy Ray James, under the title of "The Sea and Sea Images in Selected Poems of NineteenthCentury English Poetry" chooses many representative poems of sea to discuss how some English poets from the nineteenth century responded to and viewed the sea in order to connect man with his own identity and purpose (James, 1999).

Daniel P. Walden, in his paper "America at the Sea: The Influence of the Coast on Early and Antebellum American Literature" expounds the coastline has cultivated a unique cultural situation unique from that of either land or sea, but demonstrated influences from both. The evolution of American culture in the major early and antebellum cities was influenced by the entire Atlantic world. The coastline as a place where the trans-Atlantic (i.e. oceanic) and the American continent (i.e. terrestrial) impact each other, the resulting literature reflects the complexity and contradiction of this space. Therefore, the representation of the coast evolved with the changing understanding and presentation of America as a maritime nation (Walden, 2008).

Peter F. Cataldo chooses the sea novels of Edgar Allan Poe and Herman Melville to explore the black presence implicated, in his "Ghosts in the Machine: The Black/Africanist Presence in the Sea Novels of Edgar Allan Poe and Herman Melville" focusing on analyzing the characters and main content of the sea in their respective works, mainly comparing and contrasting the plots and demonstrating the way they show the black presence in their sea novels (Cataldo, 1998). 


\subsection{The Necessity of Research on Marine Literature}

In recent years, as the status of the sea continues to rise, the world has seen endless researches in the ocean. Among them, the study of marine literature also spring up. Researchers study Chinese and Western marine literature from all aspects and angles, such as the history of marine literature in various countries, in-depth study of a particular marine literature, or a comparative study of marine literature. However, in many studies that have been carried out, there are few comparative studies that combine Chinese and Western marine literary works, and among them few papers are published to explore the social reality.

This paper narrows the period down to the specific and typical 18th century, when both China and the West were undergoing major changes; choosing two typical pieces of marine literature, which have a clear overview of historical facts. Then, this paper will make comparative analysis from different aspects and angles, to explore the similarities and differences between Chinese and Western marine literature, and probe into the historical reality.

Findings of this paper will provide a new perspective for relevant studies in marine literature, and new ideas for the study of cultural differences between China and the West, which will pave the way for the future creation of marine literature.

\section{Comparison ANd CONTRAST OF Flowers in the Mirror AND GULLIVER'S TRAVELS}

\subsection{An Overview of the Two Marine Novels}

Flowers in the Mirror is written by Li Ruzhen, a famous novelist of Qing Dynasty. The book has a hundred chapters in total. The first half highlights the features of its marine literature. It mainly describes the stories of the protagonists Tang Ao, Lin Yang and others traveling to overseas countries, including their experiences in Kingdom of Women, Kingdom of Gentleman and other countries. The author adapts ancient Chinese myths and fictions, such as The Classic of Mountains and Rivers, into an intriguing story and creates a mysterious overseas world to express his own political ideas.

Gulliver's Travels is a satirical novel written by Jonathan Swift, a British writer. The novel narrates the protagonist Gulliver's four sea adventures, describing his exotic experiences in Lilliput, Brobdingnag, Laputa and Houyhnhnms. The author wrote a ridiculous and bizarre plot with rich satire and fictional fantasies, profoundly reflecting the pointless partisan struggles in the British parliament at the time, and he expresses his own ideas through the more perfect form of art.

Flowers in the Mirror and Gulliver's Travels are both classic pieces of marine literature. Both of them describe people's overseas adventures. These similarities make them more comparable when exploring the historical reality of China and the West. The two novels both criticized the corruption and tyranny of the ruling class and express their pursuit of an ideal society, meanwhile, maintaining their respective characteristics of the times and cultural traditions.

Flowers in the Mirror is a novel of Qing Dynasty in China. The Qing Dynasty was the turning point of the last feudal dynasty in our country from decline to prosperity, and also the eve of the total collapse of our feudal society for thousands of years. However, Gulliver's Travels is written in an era when the political climate in the modern history of Britain changed dramatically. The establishment of a constitutional monarchy accelerated the process of mad predation and cruel exploitation that primitive capitalists accumulated.

The key of these two novels' creation era, the critique of their content expression to the historical reality and their abundant similarities and differences all show that they will be the best model of this research.

\subsection{Critical Realism Revealed in Similarities between Flowers in the Mirror and Gulliver's Travels}

\subsubsection{Content}

The two novels both describe the protagonist travel all over the sea. The first half chapter of Flowers in the Mirror mainly about Tang Ao and his partners visiting some fantastic countries when going oversea to do foreign business; Gulliver's Travels is a story of a British doctor named Gulliver who 
sailed to several exotic countries. Although the authors of the two novels name and depict these foreign lands in different ways, similarities are still well-found.

For example, Flowers in the Mirror and Gulliver's Travels all have Kingdom of Dwarfs (Lilliput). The former novel's dwarf is eighty or nine inches while the latter in height is less than six inches. The people in Kingdom of Giant height is seven or eight feet tall while the people of Brobdingnag are twelve times larger than the average person. The people in the Kingdom of Da Reng can ride the cloud, while the country Laputa can also fly up and down freely. What's more, the two novels both have a reverse description of reality. The former writes that the Kingdom of Women regards men as women and women as men, and the ridiculous content shows the author's satire for male supremacy at that time and pursuit of the equality between men and women. And the latter's Houyhnhnms regards horses as citizens and human beings as animals, which shows the author's distain for the immoral human beings (Swift, 2008), (Ruzhen Li, 2007).

Since novels are based on social reality to a certain extent, the striking resemblance between the two novels also shows that the reality of Chinese and Western societies at that time had much in common such as the absurd corruption of the ruling class as well as the people's dissatisfaction and the protests. Flowers in the Mirror was created in 1820 during the JiaQing period. During this period, the feudal society began to be weakening. As the rule of the Qing Dynasty was corrupted, social contradictions intensified that peasant uprisings arose. The sprouting of capitalism had impact on the original feudal natural economy. And intensified land annexation caused a large number of peasants to go bankrupt in exile. Gulliver's Travels was written in 1726. Since Glorious Revolution of 1688 did not completely eradicate Britain's deep-rooted Feudalism, the subsequently established constitutional monarchy was also the result of compromise between the feudal aristocrats and the big bourgeoisie. Capitalism oppresses the people for the primitive accumulation of capital. One typical example is the Enclosure Movement which has aggravated social class conflicts (Yu Cong, 2016).

Both authors use the fictional plot to imply their inner ideal state. The Kingdom of Gentlemen in Flowers in the Mirror is a friendly and harmonious state which is written to deny the feudal officialdom and intrigues. Houyhnhnms in Gulliver's Travels has no words like "lie" and "deceive". It reveals the ruling group's corruption and depravity, satirizes the bad atmosphere in British social life and expresses the author's longing for true democracy and equality.

\subsubsection{Theme}

Both Flowers in the Mirror and Gulliver's Travels are narrations of the people's adventures on the sea. The protagonists of both novels traveled overseas and witnessed some miraculous wonders, which bring them some thought and sentiment. The authors of the two novels express their inner perceptions of social reality through exaggerated descriptions based on social reality, together with imagination to depict various fantastic settings and characters.

For example, Kingdom of Gentleman in Flowers in the Mirror is a peaceful tranquil paradise free from tactics and intrigues. People there are kind and compassionate with each other. This shows that the author longs for an ideal society, where people lead a harmonious life. In Gulliver's Travels, parties of Lilliput are at odds with each other. The king of Lilliput chose the officers by the method of skipping competition, and the officials did ridiculous performances of clowning in order to obtain a few colored threads that the king may give them. These scenes were the epitome of the Britain at the time when the endless struggles arise between the Tories and the Whigs, especially those English politicians at that time just fighting each other on some sections irrelevant to people's life. It shows the author's dislike and sarcasm about the senseless disputes among the parties.

\subsubsection{Rhetoric}

Flowers in the Mirror and Gulliver's Travels both have rich manners of expression. And they have great similarities especially in rhetorical devices, such as the exaggeration and irony. For example:

In Flowers in the Mirror, the rich force their servants to eat manure instead of three meals a day in order to save food. This shows the exaggeration technique as well as the satire on the cruelty of ruling class and the sympathy for the poor people at that time (Ruzhen $\mathrm{Li}, 2007$ ). 
In Gulliver's Travels, the officials of Lilliput claim that their dominions extend five thousand blustrugs. However, the author's explanation "about twelve miles in circumference" that their land in fact is only a tiny area of twelve miles. This reflects the author's irony about it the officials' shortsightedness and self-complacency (Swift, 2008).

\subsection{Critical Realism Revealed in Differences between Flowers in the Mirror and Gulliver's Travels}

Flowers in the Mirror and Gulliver's Travels originate in two different civilizations. Despite many similarities, there are still fundamentally different. Both of them depict authors' criticism of the real society and their respective blueprints of an ideal country. From the two perspectives, there is also a big difference between the two novels.

First of all, the two novels are different in their critical direction and degree of reality.

The Qing Dynasty in which Li Ruzhen lived carried out cultural repression through the literary inquisition. It fabricated charges to persecute the literati and imprisoned the ideology and culture. Facing with the decline of the reality, Li Ruzhen uses space-time shift method in Flowers in the Mirror. He aims to criticize the feudal dynasty through the depiction of Empress Wu Zetian. In the novel, when Wu Zetian is drinking in the snow, she suddenly orders all the flowers to bloom but the peony does not obey. Wu Zetian flew into such a rage that she had the peonies baked, and then banished Peony from Changan to Luoyang. The plot reveals the tyranny of feudal monarchy tyranny.

Swift's lifetime (1667-1745) is precisely the intricate era of British political situation. Class conflicts have become increasingly apparent. The Enclosure Movement promoted by the aristocrats and bourgeoisie deprived peasants of their lands as private property; the peasants were driven from the land and turned into the poor. Conflicts also exist in the ruling class. Whig and Troy, the two major parties in the British parliament attack each other and fight for power. In face of the dark social reality, Swift uses the trivialities of Lilliput in Gulliver's Travels to portray the British reality at the time. And he also satirizes the power-fighting of the British ruling class, the party dispute and the policy of aggression on the excuse of religious differences by means of fictional plot and superb technique of expression such as exaggeration, contrast, etc. He exposes and criticizes the pointless partisan struggles in the British parliament, the stubborn corruption of the ruling circles and the brutal violence in the colonial war.

Li Ruzhen lives in the shackles of feudalism, so Flowers in the Mirror attacks the dark side of the feudal society. Swift is influenced by bourgeois democratic thinking, so Gulliver's Travels exposes the ugly nature of capitalist society.

In addition, there is also some difference between the ideal countries illustrated in the two novels.

In Flowers in the Mirror, Kingdom of Gentleman is the author's ideal country. In Kingdom of Gentleman, sellers strive for less money, sold first-class goods; buyers strive to pay high prices, take low-class goods. Both sellers and buyers are considerate for each other. However, in the real life, people may be unscrupulous for the sake of money so their argument is completely different. The prime minister of Kingdom of Gentleman is gentle and benevolent that makes himself respected by people. These fictional plots are advised to order to criticize the domineering, corrupt feudal officialdom and the deceitful reality of society.

Swift's longing for an ideal society is mainly reflected in Houyhnhnms of Gulliver's Travels. In Houyhnhnms, the citizens, wise horses, enjoys the virtues of kindness, honesty and friendship. There are no such words as "lying" and "deception" in the language of Houyhnhnms. No one in this country knows what is "doubt" and "distrust" since here everything is real and just. Swift writes such plot to expose the corruption and depravity of the ruling class in the real word, and satirize the dark British social life. The author longs for an ideal country with the true democracy and equality of society.

\section{CONCLUSiON}

This paper chooses the two classic marine literary works: Chinese Flowers in the Mirror and Western Gulliver's Travels, to explore the historical realities that reflected in their theme, the main contents and the technique of expression. And on this basis, it also compares the critical realities reflected in 
the two novels, starting from the similarities and differences, to make a comparative analysis of the historical reality of China and the West.

This paper finds that both of these novels are a good example of the critical realism in this period. Both of their authors are based on the historical reality, imagined, combined with their own ideas and portrayed in a satirical and critical manner. They writes novels from the adventures of people in fictional ocean adventure stories, they all reflect the dark absurdity in this period and criticizes the reality in a more euphemistic way. For instance, the author of Flowers in the Mirror creates Kingdom of Gentleman which is a peace and no intrigue state to show his longing for an ideal society which without social darkness. The author of Gulliver's Travels writes about Lilliput which is a country with a ridiculous king and officials to imply the epitome of the Britain at the time and show his dislike and sarcasm about the senseless disputes among the parties. And, because of the difference between the historical reality of China and the West, there are some differences in the novels, for example, Flowers in the Mirror attacks the dark side of the feudal society and the author longs for a friendly and harmonious country which may be still ruled by emperor. However, Gulliver's Travels exposes the ugly nature of capitalist society. The author longs for an ideal country with the true democracy and equality of society.

This paper explores the critical realism of Western and Chinese marine literary works, which contributes to the comparative study of the history of China and the West as well as for the future creation of marine literary works. Through the comparison and contrast of the two marine literary works, this paper concludes that there are more or less similar historical realities in China and the West. By reading and researching, we can find out that their critique of social reality and the illusion of future ideal society are of practical significance. Even if some problems may not be solved for a time, there are still many possibilities in the future. The fantasy of a harmonious society in Flowers in the Mirror has been basically realized in China today. The desire in Gulliver's Travels for a democratic capitalist society is also basically fulfilled today in some western countries. The future marine literature can continue to present an exotic land embedded with the political aspiration of the authors based on current social reality, which can not only enrich the content of the works, to attract readers to resonate, but also tactfully put forward suggestions for social development.

\section{REFERENCES}

[1] Liu H.Y., A Brief History of China's Marine Literature. Journal of Zhejiang Ocean University (Humanities Science), 27, P 7, (2010).

[2] Zhao J. Y., Epoch Character on the Marine Literature of the Song \&Yuan Dynasty. Journal of Fujian Teachers University (Philosophy and Social Sciences Edition), 1, P 56, (2002).

[3] Guo Q. Y., On the Artistic Expression of the Seas in Notes Novel of Tang and Song Dynasties: A Case Study of The long bearded country and Gui Hao Drowning. Theory Front, 10, P192, (2013).

[4] James R. R., The Sea and Sea Images in selected poems of Nineteenth-Century English Poetry. Diss. U of Southwestern Louisiana, (1999).

[5] Walden D. P., America at the Sea: The Influence of the Coast on Early and Antebellum American Literature. Diss. U of Mississippi, (2008).

[6] Cataldo P. F., Ghosts in the Machine: The Black/Africanist Presence in the Sea Novels of Edgar Allan Poe and Herman Melville. Diss. U of New York, (1998).

[7] Sun Q., "A Comparative Study of Chinese and British and American Marine literary works in Ming and Qing Dynasties". Education Teaching Forum.3, Pp249-250, (2015).

[8] Li R. Z., Flowers in the Mirror. Xian: San Qing Publishing House, (2007).

[9] Swift J., Gulliver's Travel. Signet Classics, (2008).

[10] Cong Y., An Analysis of the Value of Flowers in the Mirror and Gulliver's Travels in Contemporary Times. Science and Technology Economic Guide, 10, P 158, (2016).

\section{AUTHORS BIOGRAPHY}

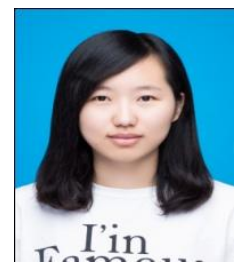

Yuhan Ye was born in Taizhou, China in 1997. She is a third-year English major in Zhejiang Ocean University. Her research interest is English culture and literature. 


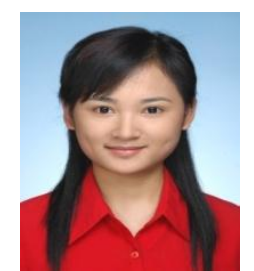

Xiaoxu CHEN was born in Zhoushan, China in 1986. She received her M.A. degree in English language and literature in Shanghai International Studies University, China. She is an lecturer in the School of Foreign Languages, Zhejiang Ocean University, China. Her current researches focus on British and American culture

Citation: Yuhan YE, Xiaoxu Chen. "Brief Analysis of Critical Realism in Chinese and Western Marine Literature". International Journal of Humanities Social Sciences and Education (IJHSSE), vol 5, no. 4, 2018, pp. 102-108 doi: http://dx.doi.org/10.20431/2349-0381.0504012.

Copyright: (C) 2018 Authors. This is an open-access article distributed under the terms of the Creative Commons Attribution License, which permits unrestricted use, distribution, and reproduction in any medium, provided the original author and source are credited. 